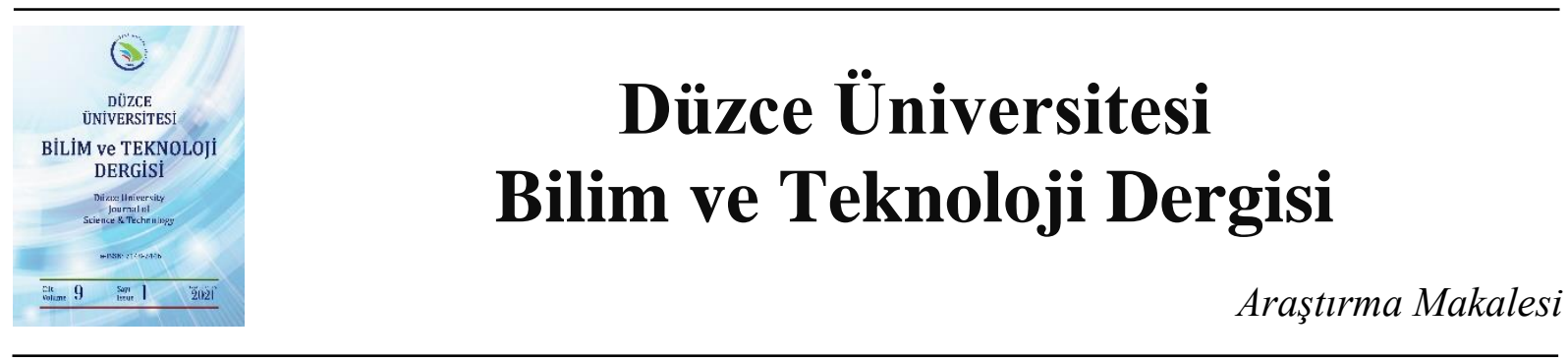

\section{Türkiye Demiryolu Yolcu Taşıma Talebinin Tahmini}

\author{
(D) Fatma ÇAKIR ${ }^{\mathrm{a}, *}$, (D) Hümeyra BOLAKAR TOSUN ${ }^{\mathrm{b}}$ \\ ${ }^{a}$ İnşaat Mühendisliği Bölümü, Mühendislik Fakültesi, Aksaray Üniversitesi, Aksaray, TÜRKiYE \\ ${ }^{b}$ İnşaat Mühendisliği Bölümü, Mühendislik Fakültesi, Aksaray Üniversitesi, Aksaray, TÜRKIYE \\ * Sorumlu yazarin e-posta adresi: fatoskerse@gmail.com \\ DOI : 10.29130/dubited.769092
}

\begin{abstract}
ÖZET
Günümüzde yolcu taşımacılığında demiryollarının payı giderek artmaktadır. Yolcu talebinin karşılanması için uygun planlamaların belirlenmesi gereklidir. Kapasiteyi karşılayacak planlamaların oluş̧urulması hem talebi karşılayacak hem de yatırımlarda uygun kararların alınmasını sağlayacaktır. Bu çalışmada, demiryolu yolcu taşımacılığı üzerinde etkili olan değişkenler kullanılarak demiryolu yolcu sayısının tahmin edilmesi amaçlanmıştır. Yolcu talebinin belirlenmesi için Çok Değişkenli Regresyon (ÇDR) analizi ve Yapay Sinir Ağları (YSA) ile iki farklı model oluşturulmuştur. İki model içinde tahmin değerleri belirlenmiştir. Hata kareleri ortalaması (MSE) ve belirleme katsayısı $\left(\mathrm{R}^{2}\right)$, performans kriterlerini, dikkate alarak en uygun tahmin YSA ile elde edilmiştir. Talep tahmininde YSA kaynak olarak kullanılabileceği görüşüne varılmıştır.
\end{abstract}

Anahtar Kelimeler: Demiryolu yolcu taşıma, YSA, ÇDR, MSE,

\section{Forecasting of Turkey Railway Passenger Transport Demand}

\begin{abstract}
Today, the share of railways in passenger transportation is increasing. Appropriate planning is required to meet passenger demand. The creation of plans to meet the capacity will both meet the demand and ensure that appropriate decisions are made in investments. In the study, it's aimed to estimate the number of rail passenger using variables that affect rail passenger transport. Two different models were created with Multivariate Regression (MR) analysis and Artificial Neural Networks (ANN) to determine passenger demand. Estimation values were determined in two models. Taking the mean of eror squares (MSE) and coefficient of determination $\left(\mathrm{R}^{2}\right)$, performance criteria, the most appropriate estimate was obtained with ANN: It's concluded that ANN can be used as a resource in demand forecasting.
\end{abstract}

Keywords: Railway passenger demand, ANN, MR, MSE

Geliş: 14/07/2020, Düzeltme: 29/11/2020, Kabul: 09/12/2020 


\section{GIRIS}

Yolcu talep tahminini, ulaştırma sistemlerinin düzenli çalışması, işletme planlaması, yolcu yoğunluğunun yönetilmesi ve gelir yönetiminin kontrol altında tutulmasını sağlamaktadır [1]. Demiryolu yolcu taşımacılığında daha iyi hizmet sunmak için hat planlama ve zamanlamanın tahmin edilmesi, yolcuların seyahat seçme ölçütlerinin belirlenmesi ve uygun yolcu akışını verecek modeller oluşturulmalıdır [2].

Talep tahminin amacı belirlenen bir zaman diliminde oluşacak talebin, temsili olarak, gerçeğe yakın değerlerin elde edilmesidir. Güncel veriler dâhilinde hata analizlerinden faydalanarak en az sapma yapan modellerin oluşturulması, gerçekçi ve uygun sonuçlara ulaşmayı etkilemektedir $[3,6]$. Talep tahmininde etkili olan değişkenlerin belirlenmesi ve bu değişkenlerin etkilerinin ölçülmesinde yapay zeka uygulamaları, nitel ve nicel yöntemler kullanılmaktadır [6,4].

Wardman [5] çalışmasında, yolcu talebi üzerinde etkili olan dış etkenler, GSYH, araç sahipliliği, yolculuk süresi, yakıt maliyetleri, nüfus ve hatlar üzerindeki özelleştirmelerin talebi etkilediğini belirtmiştir. Topuz [7] çalışmasında, toplu taşıma sistemlerini kullanan yolcuların yolculuk taleplerini belirlemek için günlük yolculuk sayılarını baz alarak yapay sinir ağları modellemeler oluşturmuş ve değişkenlerin \%80'ini eğitim, \%20'sini test aşamasında kullanmıştır. Bu modellerden en iyi sonuçların tarihlendirilmiş verileri kullanarak ileri beslemeli ă̆ yapısının verdiğini belirlemiştir. Xie vd. [1] çalışmalarında, bir güzergâh üzerinde numaralandırdığı istasyonlara gelen ve ayrılan yolcu sayısına ait geçmiş verileri kullanarak kısa vadeli planlamada yapay sinir ağlarından faydalanmışlardır. Önerdikleri DC (Divide and Conquer) yöntemi ile kısa vadeli yüksek hızlı tren yolcu akışının tahmininde başarılı sonuçlar oluşturduğunu belirlemişlerdir. Bayata vd. [8] çalışmalarında, yolcuların tercih, tutum ve memnuniyetlerine göre seyahat sıklığı talebinin belirlenmesinde Yapay Sinir Ağları (YSA), Çok Değişkenli Regresyon (ÇDR) ve Bulanık Mantık (BM) yöntemlerini kullanarak elde ettikleri sonuçları kıyaslamışlardır. YSA ve ÇDR ile analizde ankete verilen cevapların tahmin edilmesinde yapay sinir ağlarının daha iyi sonuçlar oluşturduğunu belirlemişlerdir. Gallo vd. [9] yaptıkları çalışmada, Napoli metro hattının yolcu akışını tahmin etmek için hat üzerindeki kapasitenin belirlenmesinde yapay sinir ağlarının performansının olumlu sonuçlar oluşturduğu belirlemiş̧lerdir.

\section{MATERYAL VE YÖNTEM}

\section{A. REGRESYON ANALIZI}

Regresyon analizi, iki ya da daha fazla bağımsız değişken kombinasyonunun etkilerini değerlendirerek bağımlı değişkenin alacağı değerlerin belirlenmesini sağlar. Regresyon analizinde öncelikli olarak ağırlık ya da katsayılar belirlenir. Modellemede tanımlanan bağımsız değişkenler bağımlı değişken değerlerine daha yakın sonuçlar elde etmeye ve değişkenlerin önemlerini belirlemeye yardımcı olur [10].

Korelasyon analizinde bağımlı değişken üzerindeki etkili olan bağımsız değişkenlerin ilişkisi incelenir. Bağımsız değişkenlere ait değerler artarken bağımlı değişken değerleri azalıyorsa korelasyon negatif değerler alır. Bağımlı değişken artarken bağımlı değişken de artıyorsa değişkenler arasında pozitif ilişkiyi ifade eder. Değer 1'e yaklaştıkça ilişki güçlenir, -1'e yaklaştıkça ilişki zayıflar. Hatanın belirlenmesinde tahmin ve gerçek değerler arasındaki fark hatanın kareleri toplamının en küçük değeri alacağ1 en küçük kareler yöntemi kullanılarak yeni bir doğrunun oluşturulması ile belirlenir. Oluşturulan bu doğru tüm düşey tahmin hatalarının sıfır olduğunu ve hata karelerinin toplamının en küçük değeri alacak biçimde oluşturulduğunu ifade eder. Eğer değişkenlere ait değerler uygun aralıklar içinde kalacak bir doğrunun oluşturulması için uygun değilse eğri uydurma yöntemi ile hata karelerinin toplamının minimum aralıkta kalacağı bir doğru oluşturulabilir [11]. 


\section{B. YAPAY SINIIR AĞLARI}

İnsan beyni fonksiyonlarının bilgisayarlara uyarlanmasıyla elde edilen YSA biyolojik sinir sistemlerinin davranışlarını makinalar üzerinde gerçekleştirir. Ağın temel elemanlarını girdi, toplam fonksiyonu, aktivasyon fonksiyonu ve çıktı oluşturmaktadır. Sinir hücrelerinden meydana gelen YSA nöronlar arasındaki bağlantılarla sinyaller ileterek girdi katmanından aldığı bilgileri işleyip çıktı katmanına iletir. Öğrenme, ilişkilendirme ve özellik belirleme gibi yöntemlerden faydalanarak değişkenlerden tahmin yapma, sınıflandırma, modelleme gibi farklı amaçlar için kullanılmaktadır $[12,13]$.

Günlük olayların çoğu doğrusal olmayan bir ilişki ile gerçekleşmektedir. Doğrusal olmayan modellerin çözümlenmesi için çok katmanlı ve ileri beslemeli ağlar geliştirilmiştir [12]. İleri beslemeli ağlarda girdi katmanından alınan bilgi akışı daima tek doğrultuda çıktı katmanına doğru ilerler. Toplanan bilginin ağa ilk sunulduğu yer girdi katmanıdır. Bağlantılar yoluyla ara katmana gelen bilgiyi karıştırır ve değişkenlerin yeni özelliklerini belirler. Çıktı katmanı tahminleri oluşturur ve hatayı yayar $[14-15,1]$.

İleri beslemeli geri yayılımlı öğrenmede girdi, gizli ve çıktı katman arasındaki bağlantı ağırlıklarına hatanın dağıtılması ile hata karelerinin uygun değerler almasında yardımcı olur [6]. Gerçek değerler $(\mathrm{y}(\mathrm{k}))$ ve ağ işlemlerinden sonra elde edilen çıktı değerleri $(\mathrm{o}(\mathrm{k}))$ arasındaki fark hata değerini oluşturur [16].

$\mathrm{e}(\mathrm{k})=\mathrm{y}(\mathrm{k})-\mathrm{o}(\mathrm{k})$

Ağın eğitilmesi, uygun ağırlık değerlerinin belirlenmesi ve doğruluğunu etkiler. Ağ eğitilmesindeki amaç bağımlı değişken değerinin gerçek değerlere en yakın değerlerin elde edilmesidir. Hata değerini minimum değerlere sahip olması için ağ içinde işleme devam edilir. Ancak ağ uzun süre eğitilmeye devam ederse genelleme özelliğini kaybeder [17].

İleri beslemeli yapay sinir ağlarının eğitilmesinde kullanılan en etkili yöntem olan LevenbergMarquardt yöntemidir. Levenberg-Marquardt algoritması minimum ortalama hata karelerini hesaplamak için kullanılmaktadır [18]. Newton algoritmasının performans indeksinin ikinci türevi ile oluşturulan Levenberg Marquardt, Jacobian tarafından Hessian matrisine yaklaşır. Ağ performansı hata kareleri toplamı (MSE) ile belirlenir [19]. MSE denklemi, Eşt. 2'de verilmiştir.

$\operatorname{MSE}=\frac{1}{\mathrm{~N}} \sum_{\mathrm{i}=1}^{\mathrm{n}}\left(\mathrm{A}_{\mathrm{i}}-\mathrm{F}_{\mathrm{i}}\right)^{2}$

Levenberg Marquardt algoritmasının performans indeksinin optimizasyonu; [16,18]

$\mathrm{x}_{\mathrm{k}+1}=\mathrm{x}_{\mathrm{k}}-\mathrm{A}_{\mathrm{k}}^{-1} \mathrm{~g}_{\mathrm{k}}$

Burada $A_{k}$ ve $g_{k}$ :

$A_{k}=\left.\nabla^{2} F(x)\right|_{x=x k}$

$\mathrm{g}_{\mathrm{k}}=\left.\nabla \mathrm{F}(\mathrm{x})\right|_{\mathrm{x}=\mathrm{xk}}$

Eşt. (4), (5), (6)'da $\mathrm{x}$ değişkeni ağın ağırlıklarını, $\nabla^{2} F(x)$ Hessian matrisini, $\nabla F(x)$ eğimi, $\mathrm{F}(\mathrm{x})$ hata kareleri toplamını ifade etmektedir. Ağın eğitiminde ağın öğrenmesi için başlangıçta ağırlıklar değerleri küçük ve rastgele seçilir. Hata değeri minimum olana kadar x ağırlık değerleri değiştirilerek uygun ağ modellemesi oluşturulur. İşlem devamındaki bilginin detayları Daniel et al. [18] çalışmasından ulaşılabilir. 


\section{BULGULAR VE TARTIȘMA}

\section{A. DEMIRYOLU YOLCU TAŞIMA TALEBINE AITT BULGULAR}

Demiryolu yolcu talebini etkileyen ana faktör GSYH olduğu gibi ayrıca araç sahipliliği, nüfus, yakıt maliyetleri ve araba ile yolculuk süreleri gibi faktörlerde etkilidir [5]. Çalışma da demiryolu yolcu taşımacılığında etkili faktörler Statistica 12.0 paket programı kullanılarak regresyon analizi ve YSA ile iki farklı şekilde modellenmiştir. Değişkenler 1998-2018 zaman aralığındaki veriler kullanılarak oluşturulmuştur. Veriler TUIK, KGM, TCDD resmi siteleriden temin edilmiştir. Performans kriteri olarak determinasyon katsayısı ve hata kareleri ortalamasından faydalanılmıştır. Verilerin ve elde edilen değerlerin yorumlanması için değişkenlerin anlamlılık testi ve genel model anlamlılığı $\mathrm{F}$ testi \%5 önem aralığında tutularak modellenmiştir.

Bağımlı değişkeni, Demiryolu Yolcu Sayısı (DYS); bağımsız değişken olarak kişi başına düşen Gayri Safi Yurtiçi Hasıla (GSYH), Nüfus (N), Karayolu Yolcu Sayısı (KYS), Otomobil Sayısı (OS), Motorlu Taşıt Sayısı (KMTS), Demiryolu Hat Uzunluğu (DHU), Demiryolu Yolcu Vagon Sayısı (DYVS), Demiryolu Yolcu Vagon Kapasitesi (DYVK), Demiryolu Yolcu Taşıma Giderleri (DYTG) oluşturmaktadır. Model verileri Çizelge 7.'den incelenebilir.

\section{B. ÇOKLU REGRESYON ANALIZİ}

Çoklu regresyon analizinin amacı bağımsız değişkenlerdeki değişimin bağımlı değişken üzerindeki etkisini açıklamak ve tahmin etmektir. Açıklama ve tahmin ayrı ayrı çözümler için kullanıldığı gibi aynı problemde ikisi de uygulanabilir. Esnek ve uyarlanabilir olduğu içinde neredeyse bütün bağımlı değişken ile ilgili işlemlerde kullanılır [20].

Korelasyon analizinde bağımlı değişken üzerinde etkili olan bağımsız değişkenlerin ilişkisi [-1, 1] aralığın da değerler alır. Değişkenler arasındaki ilişki 1'e yaklaştıkça ilişki güçlenir, -1'e yaklaştıkça zayıflar. Buna bağlı olarak korelasyon katsayısı 0,968 olarak hesaplanmış olup değişkenler arasında ilişki güçlüdür. Tablo 1.'de korelasyon analizi tablosuna göre demiryolu yolcu vagon sayısı hariç diğer değişkenler ile bağımlı değişken arasında pozitif bir ilişki mevcuttur.

Tablo 1. Korelasyon analizi

\begin{tabular}{ccccccccccc}
\hline & GSYH & N & KYS & KMTS & OS & DHU & DYVS & DYVK & DYTG & DYS \\
\hline GSYH & 1,00 & & & & & & & & & \\
\hline N & 0,97 & 1,00 & & & & & & & & \\
\hline KYS & 0,92 & 0,89 & 1,00 & & & & & & & \\
\hline MTS & 0,98 & 0,99 & 0,92 & 1,00 & & & & & & \\
\hline OS & 0,99 & 0,98 & 0,93 & 0,99 & 1,00 & & & & & \\
\hline DHU & 0,93 & 0,94 & 0,9 & 0,95 & 0,95 & 1,00 & & & & \\
\hline DYVS & 0,22 & 0,39 & 0,16 & 0,34 & 0,29 & 0,21 & 1,00 & & & \\
\hline DYVK & 0,9 & 0,92 & 0,84 & 0,92 & 0,93 & 0,95 & 0,20 & 1,00 & & \\
\hline DYTG & 0,89 & 0,96 & 0,8 & 0,95 & 0,93 & 0,89 & 0,51 & 0,89 & 1,00 & \\
\hline DYS & 0,84 & 0,76 & 079 & 0,8 & 0,82 & 0,87 & $-0,09$ & 0,8 & 0,67 & 1,00 \\
\hline
\end{tabular}

Regresyon analizi sonucunda sadece nüfus ve demiryolu hat uzunluğu değişkenlerinin bağımlı değişken üzerinde daha önemli olduğu ve bazı değişken değerlerinin pozitif olması gerekirken negatif değerler aldığı belirlenmiştir. Regresyon analizi sonucu Tablo 2'de belirtilmiştir. Regresyon analizinin $\mathrm{t}$ testi, kritik $\mathrm{t}$ değerinden ve genel anlamlılık değerinin $\mathrm{F}$ kritik büyük olması $\mathrm{H}_{0}$ yani sıfır hipotezini reddetmekte ve anlamlı bir ilişkinin var olduğunu bildirmektedir. Genel anlamlılığın belirlenmesi için varyans analizi kullanılmaktadır [21]. 
Tablo 2. Çoklu doğrusal regresyon analizi sonuçları

\begin{tabular}{ccccccc}
\hline $\mathbf{N = 2 1}$ & $\mathbf{b}^{*}$ & Std. hata $\mathbf{b}^{*}$ & $\mathbf{B}$ & Std. hata $\mathbf{b}$ & t-dĕgeri & p-değeri \\
\hline Sabitler & & & 21498,99 & 13318,25 & 1,61425 & 0,134768 \\
\hline GSYH & 1,675 & 1,292 & 0,16 & 0,13 & 1,296 & 0,221 \\
\hline $\mathbf{N}$ & $-2,680$ & 1,111 & $-0,59$ & 0,24 & $-2,411$ & 0,0035 \\
\hline KYS & $-0,252$ & 0,252 & $-0,01$ & 0,01 & $-0,998$ & 0,339 \\
\hline KMTS & $-1,136$ & 1,882 & $-0,00$ & $-0,00$ & $-0,604$ & 0,558 \\
\hline OS & 1,934 & 2,677 & 0,00 & 0,00 & 0,722 & 0,485 \\
\hline DHU & 1,201 & 0,325 & 2,24 & 0,61 & 3,692 & 0,0035 \\
\hline DYVS & 0,098 & 0,171 & 2,83 & 4,94 & 0,572 & 0,578 \\
\hline DYVK & $-0,185$ & 0,39 & $-0,01$ & 0,02 & $-0,474$ & 0,645 \\
\hline DYTG & 0,266 & 0,477 & 0,00 & 0,00 & 0,558 & 0,587 \\
\hline
\end{tabular}

( $\mathrm{b}^{*}$ : Standardize edilmemiş beta, B: standardize edilmiş beta)

Tablo 3. Varyans analizi

\begin{tabular}{cccccc}
\hline & Kareler Top. & Serbestlik D. & Ort. Kareler & F & p-değeri \\
\hline Regresyon & 27964235 & 9 & 3107137 & 18,11109 & 0,000023 \\
\hline Hatalar & 1887159 & 11 & 1715560 & & \\
\hline Toplam & 29851394 & & & & \\
\hline
\end{tabular}

Değişkenlerin $t$ testi değeri 1,614 olarak belirlenmiştir. Kritik $t$ değeri $t$ tablosundan $t_{\alpha,(n-2)}$ kuralıyla 1,729 değeri bulunmuştur. Ancak tablo değeri t testi değerinden büyüktür. Bunun için genel anlamlılık değeri incelenmiştir. F tablosundan önem düzeyi 0,05 olan $F$ kritik değeri 3,11 olarak bulunmuştur. $F$ hesap değeri $(18,11)$ kritik değerden büyük olduğu için de sıfır hipotezi reddedilmiş ve modelin anlamlı olduğu kanıtlanmıştır.

Regresyon analizi sonucunda elde edilen grafikler ile de değişkenler arasındaki bağıntılar kolay biçimde yorumlanabilir. Tahmin değerleri ile gerçek değerlerin ve hata dağılımlarının sıfır çizgisine yakın olduğu, hata histogramında iki ucu kapalı ve simetrik bir dağılım göstermektedir.

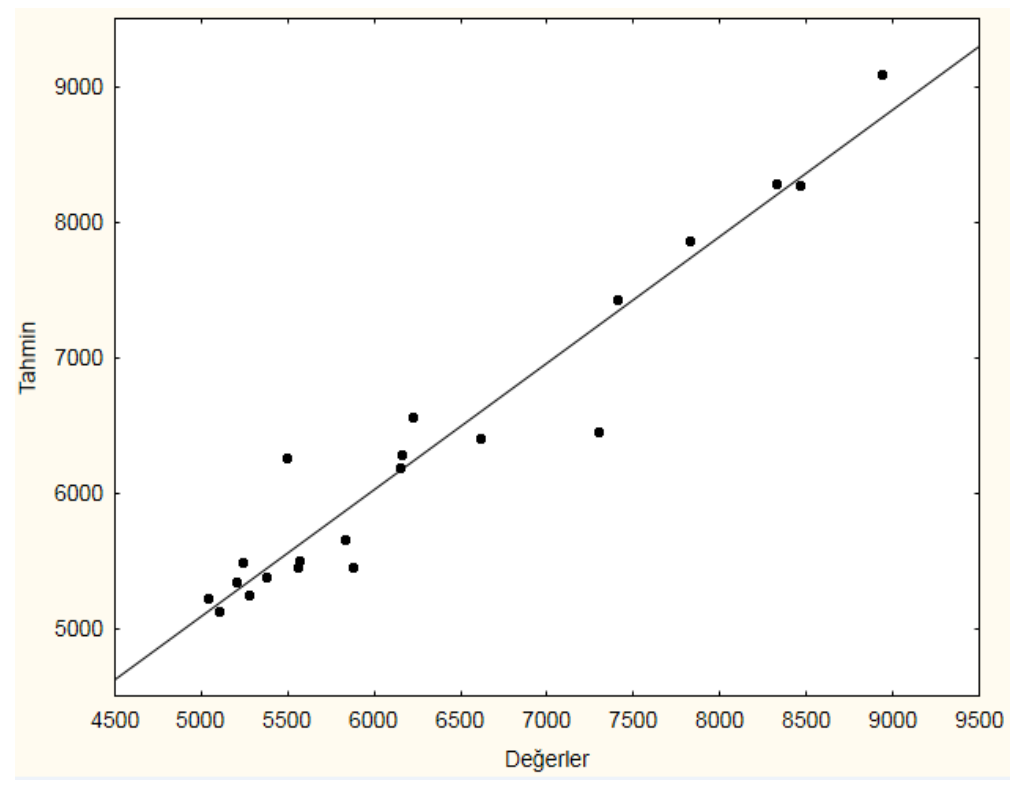

Şekil 1. ÇDR tahmin ve gerçek değerler arasındaki bağlantı 


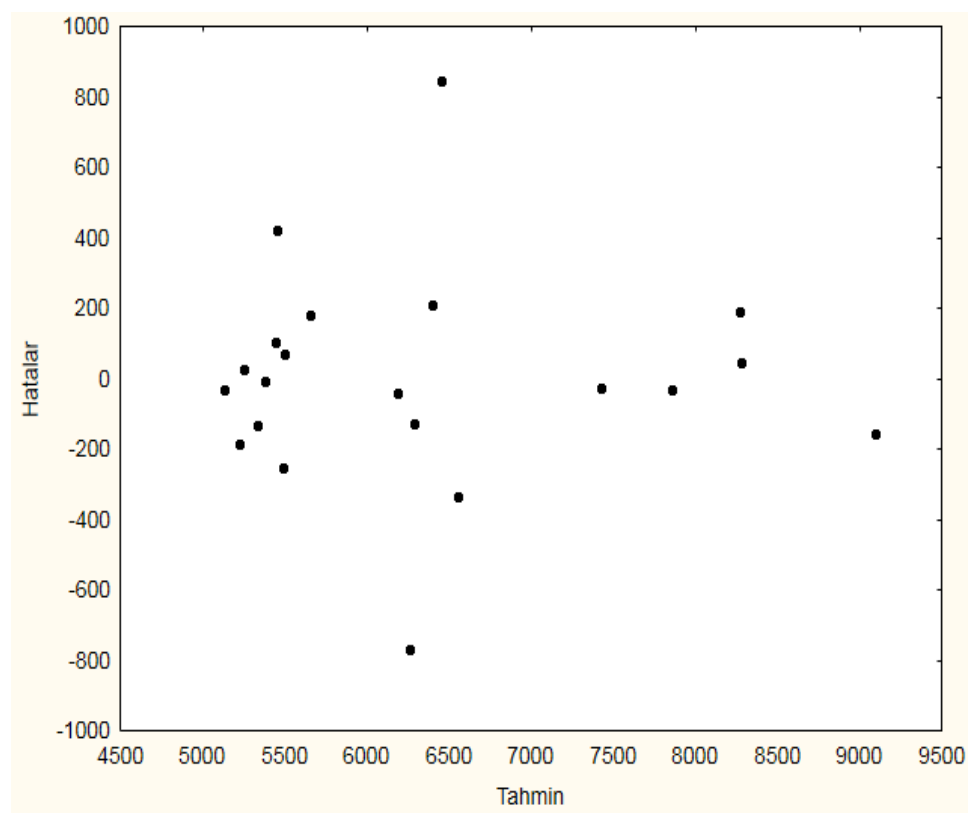

Şekil 2. ÇDR hata-tahmin dağllımı

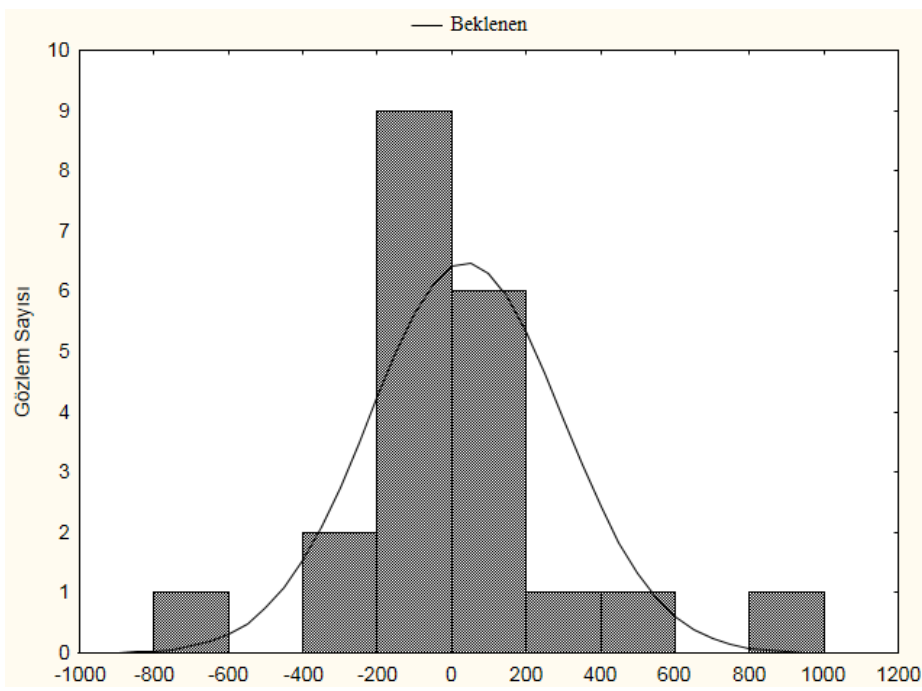

Şekil 3. ÇDR hata histogramı

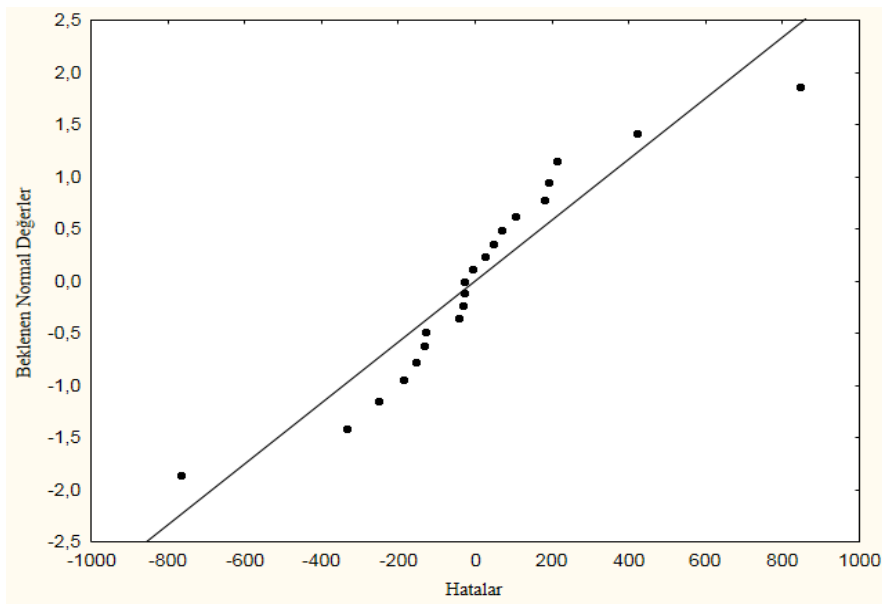

Şekil 4. ÇDR Hata normal olasılığl 


\section{YAPAY SİNIR AĞLARI}

Yapay sinir ağlarının tercih edilmesinde ki asıl sebep daha önceki çalışmalardan da yola çıkarak analiz soncunda tutarlı gerçeğe daha yakın değerler oluşturmasıdır. Yapay sinir ağlarıyla analizde ağın başlangıçta eğitilmesi deneme-yanılma yoluyla belirlenerek istenilen çıktıya ait uygun koşulu sağlayana kadar ağırlık değerleri değiştirilerek model tespit edilmeye çalışılır [12].

Çalışmada, hata değerlerini ağırlıklara yayarak işlem yaptığı için ileri beslemeli geri yayılmalı ă̆ yapısı kullanılmıştır. Girdi katmanında 9 bağımsız değişken ve bu değişkenlerin etkilediği 1 bağımlı değişken bulunmaktadır. Değişkenlerin \%80 eğitim, \%20 test için Levenberg- Marquardt algortimas1 kullanılarak 1000 iterasyonla eğitilmiştir. Ağda gizli katmanda hiperbolik tanjant çıktı katmanında log-sigma aktivasyon fonksiyonu kullanılmıştır. Ağ eğitildikten sonra uygun ağ yapısının 5 nöronlu gizli katmandan oluştuğu belirlenmiştir. Hiperbolik tanjant ve sigmoid denklemleri [12] sırasıyla Eşt. 6 ve 7'de verilmiştir.

$F(N e t)=\left(\frac{e^{\mathrm{Net}^{\mathrm{N}}}+\mathrm{e}^{-\mathrm{Net}}}{\mathrm{e}^{\mathrm{Net}}-\mathrm{e}^{-\mathrm{Net}}}\right)$

$\mathrm{F}(\mathrm{Net})=\frac{1}{1+\mathrm{e}^{-\mathrm{Net}}}$

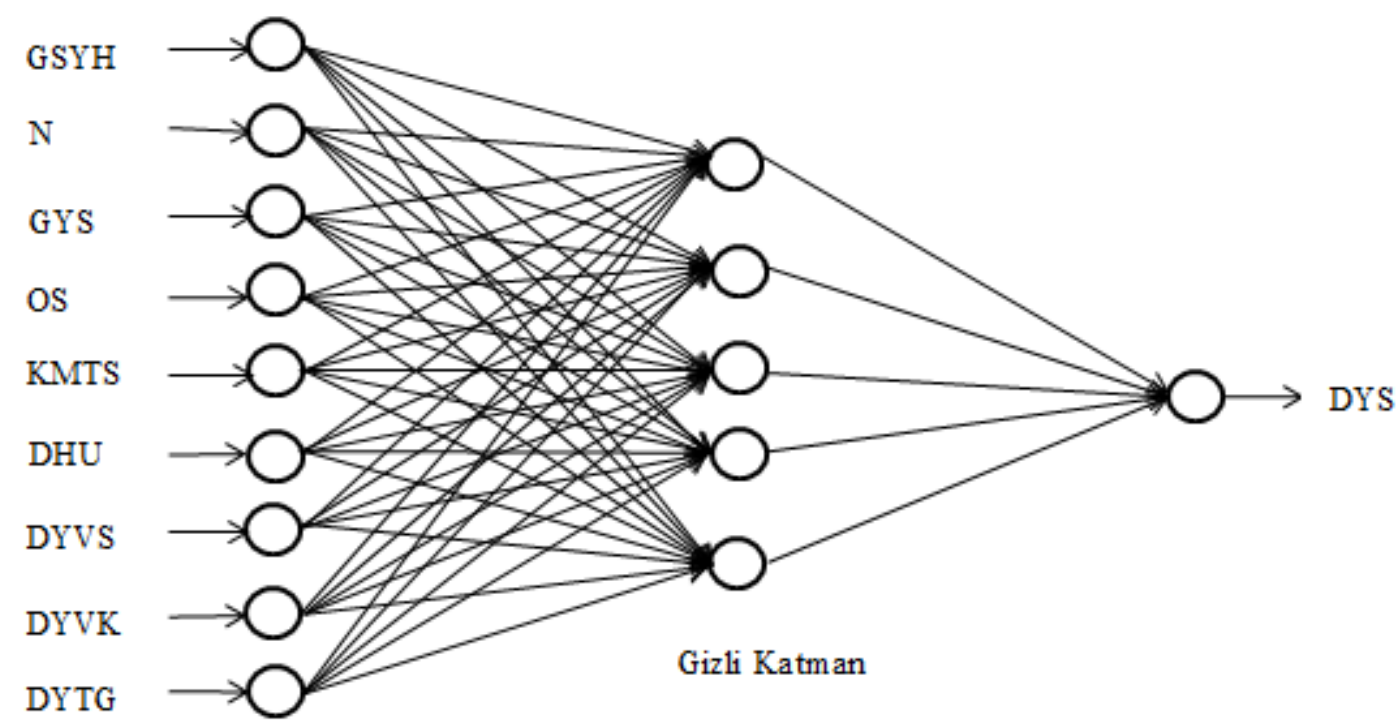

Şekil 5. Modelin yapay sinir ağı mimarisi

Modelin genel denklemi:

$\left.\mathrm{DYS}=\mathrm{f}_{2}\left[\mathrm{w}_{2}\right] \mathrm{f}_{1}\left\{\mathrm{w}_{1}\left[\begin{array}{c}\mathrm{GSYH} \\ \mathrm{N} \\ \mathrm{KYS} \\ \mathrm{KMTS} \\ \mathrm{OS} \\ \mathrm{DHU} \\ \text { DYVS } \\ \text { DYVK } \\ \text { DYTG }\end{array}\right]+\left[\mathrm{b}_{1}\right]\right\}+\left[\mathrm{b}_{2}\right]\right\}$

Ağırlık ve bias değerleri Tablo 4.’de verilmiştir. 
Tablo 4. Ağırlık ve bias dĕgerleri

\begin{tabular}{|c|c|c|c|c|c|c|}
\hline & 2.1 & 2.2 & 2.3 & 2.4 & 2.5 & 3.1 \\
\hline Bias & & & b1 & & & b2 \\
\hline & 3,3799 & 6,5265 & $-5,9584$ & $-7,0501$ & $-3,5902$ & 2,5046 \\
\hline Ă̆ırlıklar & & & w1 & & & w2 \\
\hline 1.1 & $-3,0549$ & $-7,5441$ & $-2,7439$ & 7,1031 & $-3,7086$ & \\
\hline 1.2 & $-2,8612$ & $-1,989$ & $-3,1354$ & $-1,9574$ & 3,8157 & \\
\hline 1.3 & $-2,2259$ & 18,0586 & $-2,8815$ & $-5,3261$ & $-0,5144$ & \\
\hline 1.4 & $-3,0234$ & $-4,2367$ & $-3,2471$ & 2,2257 & $-0,6555$ & \\
\hline 1.5 & $-3,1253$ & $-4,7918$ & $-3,1277$ & 3,8394 & $-2,4799$ & \\
\hline 1.6 & $-4,4021$ & $-11,31$ & $-4,7547$ & 2,9535 & 0,2609 & \\
\hline 1.7 & 1,3429 & 6,964 & $-4,019$ & 4,9553 & 0,9279 & \\
\hline 1.8 & $-2,9446$ & 8,1304 & $-1,7576$ & $-3,7249$ & 1,5453 & \\
\hline 1.9 & $-2,8045$ & $-0,5274$ & $-3,2545$ & 1,6393 & 2,5413 & \\
\hline 2.1 & & & & & & 2,9522 \\
\hline 2.2 & & & & & & $-10,3417$ \\
\hline 2.3 & & & & & & $-3,2518$ \\
\hline 2.4 & & & & & & 5,2848 \\
\hline 2.5 & & & & & & $-6,059$ \\
\hline
\end{tabular}

Ağın girdi katmanını oluşturan değişkenlerin bağımlı değişken üzerindeki etkisi duyarlılık analizi ile belirlenmiştir. Duyarlılık analizi sonucunda en önemli değişkenin gayrisafi yurtiçi hasıla olduğu tespit edilmiştir. Diğer değişkenlerin de önem derecesi sırayla karayolu yolcu sayısı, nüfus, motorlu taşıt sayıs1, demiryolu yolcu vagon sayıs1, otomobil sayısı, demiryolu hat uzunluğu, demiryolu yolcu vagon kapasitesi ve demiryolu yolcu taşıma giderleri olarak belirlenmiştir.

Tablo 5. Duyarlılık analizi

\begin{tabular}{cccccccccc}
\hline & GSYH & N & KYS & KMTS & OS & DHU & DYVS & DYVK & DYTG \\
\hline Oran & 208,88 & 178,66 & 175,71 & 129,58 & 49,63 & 46,90 & 46,85 & 33,88 & 24,49 \\
\hline Derece & 1 & 2 & 3 & 4 & 5 & 6 & 7 & 8 & 9 \\
\hline
\end{tabular}

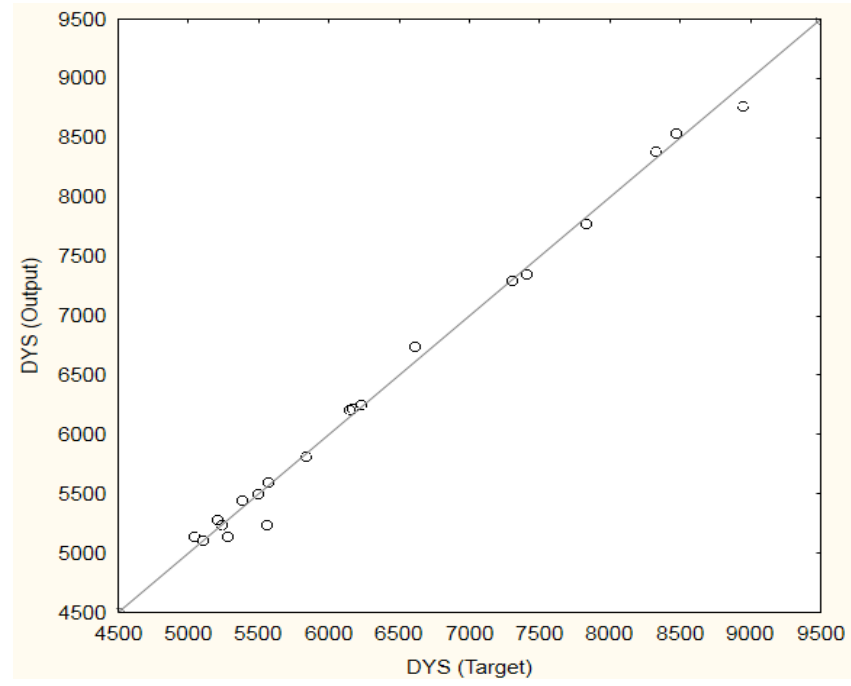

Şekil 6. YSA tahmin ve gerçek değerler arasındaki bağlantı 


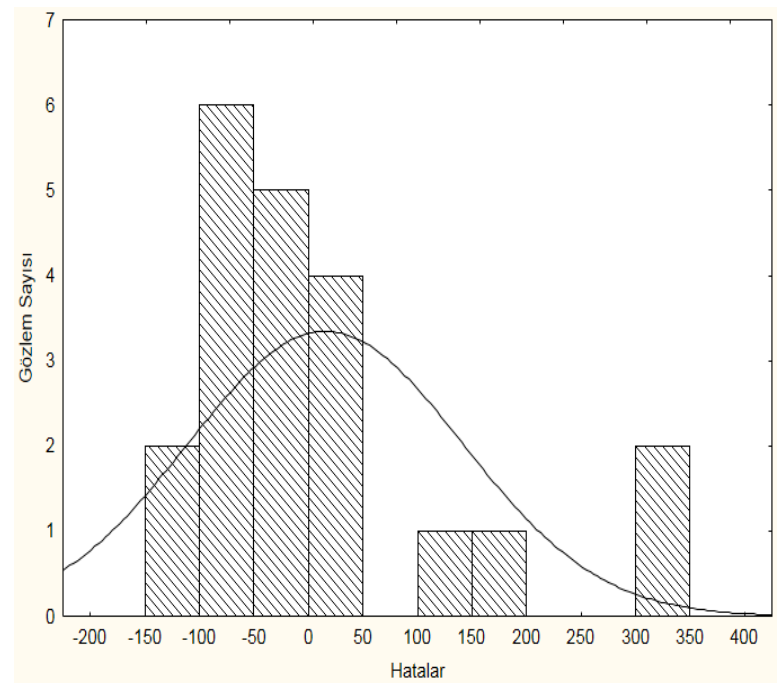

Şekil 7. YSA hata histogramı

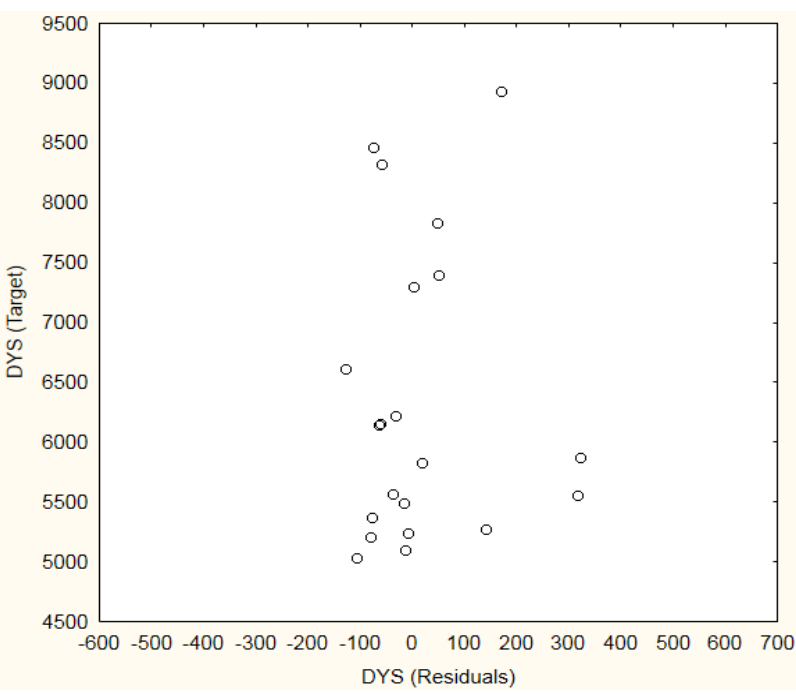

Şekil 8. YSA hata dă̆̆llımı

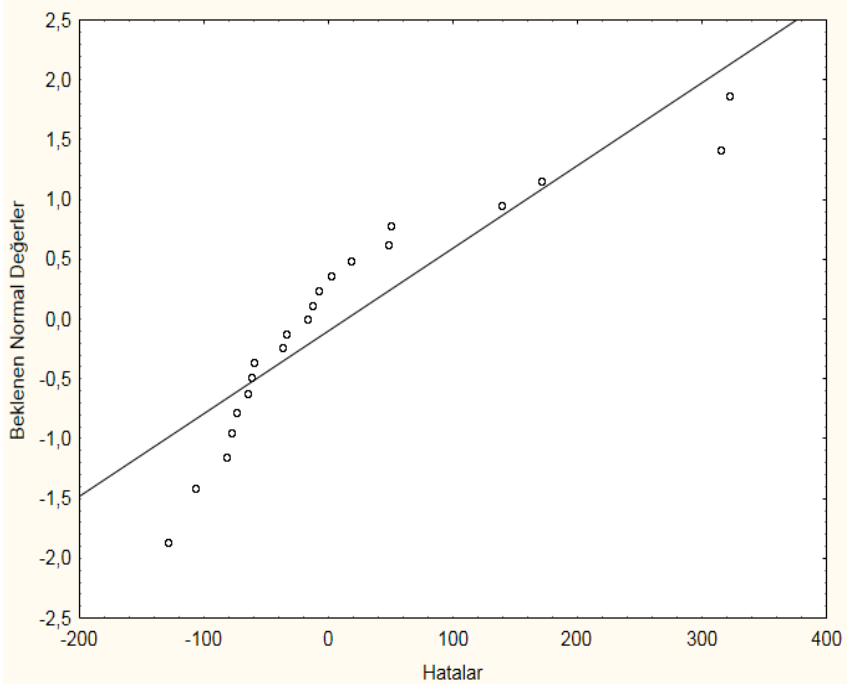

Şekil 9. Hata olasıllğgl 
YSA ait hata dağılımının sıfır çizgisi üzerine yakın, hata histogramının sola doğru açık olduğu görülmüştür. Ancak sıfır hata frekansının yüksek ve tahmin değerlerinin uyumlu sonuçlar oluşturduğu belirlenmiştir.

Tablo 6. ÇDR ve YSA tahmin de ğerleri

\begin{tabular}{cccc}
\hline Yıllar & Gözlem Değerleri & Tahmin (ÇDR) & Tahmin (YSA) \\
\hline $\mathbf{1 9 9 8}$ & 6161 & 6288,886 & 6222,649 \\
\hline $\mathbf{1 9 9 9}$ & 6146 & 6187,531 & 6211,235 \\
\hline $\mathbf{2 0 0 0}$ & 5833 & 5663,119 & 5815,466 \\
\hline $\mathbf{2 0 0 1}$ & 5568 & 5497,821 & 5604,949 \\
\hline $\mathbf{2 0 0 2}$ & 5204 & 5338,458 & 5285,887 \\
\hline $\mathbf{2 0 0 3}$ & 5878 & 5455,364 & 5555,863 \\
\hline $\mathbf{2 0 0 4}$ & 5237 & 5489,750 & 5244,929 \\
\hline $\mathbf{2 0 0 5}$ & 5036 & 5223,142 & 5142,698 \\
\hline $\mathbf{2 0 0 6}$ & 5277 & 5251,882 & 5137,734 \\
\hline $\mathbf{2 0 0 7}$ & 5553 & 5448,3541 & 5237,726 \\
\hline $\mathbf{2 0 0 8}$ & 5097 & 5130,449 & 5109,968 \\
\hline $\mathbf{2 0 0 9}$ & 5374 & 5380,101 & 5452,331 \\
\hline $\mathbf{2 0 1 0}$ & 5491 & 6258,757 & 5507,757 \\
\hline $\mathbf{2 0 1 1}$ & 7300 & 6455,157 & 7298,056 \\
\hline $\mathbf{2 0 1 2}$ & 6612 & 6400,106 & 6741,509 \\
\hline $\mathbf{2 0 1 3}$ & 6225 & 6558,769 & 6258,591 \\
\hline $\mathbf{2 0 1 4}$ & 7401 & 7429,261 & 7351,248 \\
\hline $\mathbf{2 0 1 5}$ & 8326 & 8278,461 & 8385,498 \\
\hline $\mathbf{2 0 1 6}$ & 7829 & 7858,814 & 7781,125 \\
\hline $\mathbf{2 0 1 7}$ & 8465 & 8274,562 & 8539,276 \\
\hline $\mathbf{2 0 1 8}$ & 8938 & 9092,175 & 8766,929 \\
\hline
\end{tabular}

İki modellemeye ait kıyaslamanın yapılabilmesi için hata kareleri ortalaması MSE ve belirleme katsayısı kullanılmıştır. Regresyon ve yapay sinir ağlarına ait hata kareleri toplamı ve belirleme katsayısı değerleri incelendiğinde modelin açıklanması için oldukça yeterlidir. Bağımlı değişkenin gerçek değerleri ile tahmin değerleri arasındaki hata değerleri düşük değerli ve model performansı iyi bir değere sahiptir. Ancak modelde yapay sinir ağlarının performansı, bağımlı değişkeni açıklama oranı ve hata kareleri ortalaması, regresyon analizine göre daha iyi performans gösterdiği açık bir şekilde görülmektedir.

Tablo 6. Model kıyaslama

\begin{tabular}{ccc}
\hline Model & $\begin{array}{c}\mathbf{R}^{\mathbf{2}} \\
(\boldsymbol{\%})\end{array}$ & $\mathbf{M S E}$ \\
\hline Regresyon & 93,7 & 199,727 \\
\hline YSA & 98,9 & 87,149 \\
\hline
\end{tabular}


Tablo 7. Analiz verileri

\begin{tabular}{|c|c|c|c|c|c|c|c|c|c|c|}
\hline YIllar & GSYH & N & GYS & OS & KMTS & DHU & DYVS & DYVK & DYTG & DYS \\
\hline 1998 & 1151 & 63391 & 186159 & 3838288 & 116 & 8607 & 1046 & 96534 & 69505 & 6161 \\
\hline 1999 & 1697 & 64337 & 175236 & 4072326 & 120 & 8682 & 1040 & 94461 & 113437 & 6146 \\
\hline 2000 & 2656 & 65293 & 185681 & 4422180 & 129 & 8671 & 1038 & 121049 & 176457 & 5833 \\
\hline 2001 & 3766 & 66249 & 168211 & 4534803 & 130 & 8671 & 1031 & 119652 & 278520 & 5568 \\
\hline 2002 & 5445 & 67205 & 163327 & 4600140 & 130 & 8671 & 1013 & 115591 & 388287 & 5204 \\
\hline 2003 & 7007 & 68161 & 164311 & 4700343 & 133 & 8697 & 1102 & 111372 & 444806 & 5878 \\
\hline 2004 & 8536 & 69117 & 174312 & 5400440 & 151 & 8697 & 1129 & 112094 & 539658 & 5237 \\
\hline 2005 & 9844 & 70063 & 182152 & 5772745 & 162 & 8697 & 1131 & 111375 & 570470 & 5036 \\
\hline 2006 & 11389 & 70500 & 187593 & 6140992 & 175 & 8697 & 1123 & 108199 & 618934 & 5277 \\
\hline 2007 & 12550 & 70586 & 209115 & 6472156 & 184 & 8697 & 1137 & 108330 & 702571 & 5553 \\
\hline 2008 & 14001 & 71517 & 206098 & 6796629 & 192 & 8699 & 1122 & 118824 & 729204 & 5097 \\
\hline 2009 & 13870 & 72561 & 212464 & 7093964 & 197 & 9080 & 1132 & 122203 & 823217 & 5374 \\
\hline 2010 & 15860 & 73722 & 226913 & 7544871 & 205 & 9594 & 1131 & 136552 & 835343 & 5491 \\
\hline 2011 & 18788 & 74724 & 242265 & 8113111 & 215 & 9642 & 1134 & 137860 & 926599 & 7300 \\
\hline 2012 & 20880 & 75627 & 258874 & 8648875 & 225 & 9642 & 1125 & 138769 & 1004647 & 6612 \\
\hline 2013 & 23766 & 76667 & 268178 & 9283923 & 234 & 9718 & 1135 & 159171 & 1076685 & 6225 \\
\hline 2014 & 26489 & 77696 & 276073 & 9857915 & 242 & 10087 & 1125 & 165864 & 1197772 & 7401 \\
\hline 2015 & 29899 & 78741 & 290734 & 10589337 & 254 & 10131 & 1124 & 167765 & 1360063 & 8326 \\
\hline 2016 & 32904 & 79815 & 300852 & 11317998 & 264 & 10131 & 1089 & 170105 & 1436476 & 7829 \\
\hline 2017 & 38732 & 80811 & 314734 & 12035978 & 275 & 10207 & 1080 & 172015 & 1068884 & 8465 \\
\hline 2018 & 45750 & 82004 & 329363 & 12398190 & 279 & 10315 & 1047 & 158650 & 1144294 & 8938 \\
\hline
\end{tabular}

\section{IV.SONUC}

Çalışma da demiryolu yolu taşıma talebine ait değerler üzerinde etkili olduğu tespit edilen demiryolu hat uzunluğu, nüfus, gayrisafi yurtiçi hasıla, karayolu yolcu taşımacılığında kullanılan motorlu taşıt sayıs1, otomobil sayısı, demiryolu yolcu taşımada kullanılan vagon sayısı ve kapasitesi, demiryolu yolcu taşıma giderleri ve karayolu yolcu sayısından oluşan bağımsız değişkenlerden oluşmaktadır. Analiz için çok değişkenli regresyon analizi ve yapay sinir ağlarından faydalanılmıştır. İki model içinde performans kriteri olarak hata kareleri ortalaması (MSE) kullanılmıştır.

Analiz sonucunda;

1. Regresyon analizinde nüfus ve demiryolu hat uzunluğu değişkenlerinin bağımlı değişken üzerindeki ilişkilerinin anlamlı olduğu, bazı değişkenlerin pozitif değerler alması beklenirken negatif değerler aldığı belirlenmiştir.

2. Regresyon analizi belirleme katsayısı $\left(\mathrm{R}^{2}\right)$ ve korelasyon katsayısı değerleri sırasıyla \%93,7 ve \%96,8’dir. Bu durumdan da regresyon analizinin modeli açıklamada yeterli olduğu görülmektedir.

3. Değişkenler arasında demiryolu yolcu vagon sayısı hariç pozitif bir mevcuttur. Demiryolu yolcu vagon sayısının belirlenen yıllar içinde veri değerlerinde azalmalardan kaynaklı negatif bir ilişki olduğu düşünülmektedir.

4. Analizde hesaplanan $\mathrm{t}$ testi değeri tablo değerinden küçüktür. $\mathrm{Bu}$ yüzden $\mathrm{F}$ testi de -genel anlamlılık- incelenmiştir.

5. $\quad \mathrm{F}$ testi $\% 95$ güven aralığında test edildiğinde, hesaplanan $\mathrm{F}$ değeri kritik $\mathrm{F}$ tablo değerinden büyük olduğu belirlenmiştir. Böylece sıfir hipotezi reddedilmiş ve modelin anlamlı olduğu kanitlanmıştır. 
6. Regresyon analizinde elde edilen tahmin değerlerinde gerçek değere yakın değerlerin oluştuğu ve hata kareleri ortalaması (MSE) 199,727 olarak belirlenmiştir.

7. Duyarlılık analizi sonucunda bağımlı değişken üzerinde etkili olan en önemli değişkenin Wardman'ın [5], çalışmasında belirttiği gibi gayrisafi yurtiçi hasıla olduğu görülmüştür. Diğer değişkenler de önem derecesine göre sırasıyla karayolu yolcu sayısı, nüfus, motorlu taşıt sayısı, demiryolu yolcu vagon sayısı, otomobil sayıs1, demiryolu hat uzunluğu, demiryolu yolcu vagon kapasitesi ve demiryolu yolcu taşıma giderleri olduğu gözlemlenmiştir.

8. Modellere ait hata dağılımının her iki analiz içinde sıfır çizgisi üzerine yakın olduğu, hata histogramının regresyon analizinde sağ ve sol yönünde açık olmadığı, yapay sinir ağlarında ise sola doğru açık olduğu görülmüştür. Ancak sıfır hata frekansının yüksek olduğu ve tahmin değerlerinin uyumlu sonuçlar oluşturduğu belirlenmiştir.

9. YSA ile oluşturulan tahmin değerlerine ait hata kareleri ortalaması 87,149 olarak hesaplanmıştır.

10. İki modelde performans kriterlerine ait değerler kıyaslandığında yapay sinir ağlarının belirleme katsayısı değeri daha yüksek ve hata kareleri ortalamasının daha düşük değerlere sahip olduğu belirlenmiştir.

Yapay sinir ağlarının hatayı yayarak minimum seviyede tutması ve doğrusal olmayan problemlerin çözümündeki performansına dayanarak bağımsız değişkenlerin bağımlı değişkeni açıklamada daha iyi olduğu ve gerçek değerlere yakın değerleri elde etmede daha iyi sonuçlar oluşturduğu görülmüştür. Böylece demiryolu yolcu planlamada gerçeği yansıtan değerler elde ettiği için kaynak olarak kullanılması önerilmektedir.

\section{V.KAYNAKLAR}

[1] M. Xie, X. Li, W. Zhou and Y. Fu,. "Forecasting the Short-Term Passenger Flow on High Speed Railway with Neural Networks," Computational Intelligence and Neuroscience, c. 2014, ss. 18, 2014.

[2] G. Hu, W. Liu, and H. Yang, "A reliability-based Assignment Method for Railway Networks with Heterogeneous Passenger," Transportation Research Part C: Emerging Technologies, c. 93, ss. 501-524, 2018.

[3] M. Karahan, "İstatistiksel Tahmin Yöntemleri: Yapay Sinir Ağları Metodu ile Ürün Talep Tahmini Uygulaması,” Doktora Tezi, Selçuk Üniversitesi, 2011.

[4] B. Kobu, Üretim Yönetimi, 17. Bask1, İstanbul, 2014.

[5] M. R. Wardman, "Demand for Rail Travel and The Effects of External Factors," Transportation Research Part E: Logistics and Transportation Review, c. 42, s. 3, ss. 129-148, 2006.

[6] S. P. Yalçın, "Talep Yönetimi, Dağıtımı ve Tedarik Zinciri Performansı Yönetim Uygulamalarının Tedarik Zinciri Performansı Üzerindeki Etkileri," Yüksek Lisans Tezi, Başkent Üniversitesi, 2013.

[7] S. Topuz, "İstanbul İlindeki Toplu Taşıma Yolculuk Taleplerinin Yapay Sinir Ağlarıyla Modellenmesi,” Yüksek Lisans Tezi, İstanbul Teknik Üniversitesi, 2008. 
[8] H. F. Bayata, H. N. Sağlamyürek ve O. Ü. Bayrak, "Demiryolu Yolcularının Tutum ve Davranışlarının Farklı İstatistiksel Yöntemler ile Modellenmesi," Iğdır Üniversitesi Fen Bilimleri Enstitüsü Dergisi, c. 8, s. 2, ss. 141-151, 2018.

[9] M. Gallo, G.D. Luca, L. D'acierno and M. Botte, "Artificial Neural Networks for Forecasting Passenger Flows on Metro Lines," Sensors, c. 19, s. 15, ss. 1-14, 2019.

[10] T.J. Archdeacon, Correlation and regression analysis: a historian's guide, 1. Edition, America, 1994.

[11] S. Üreten, Üretim/Isşlemler Yönetimi, 5. Bask1, Gazi Kitabevi, Ankara, 2006.

[12] E. Öztemel, Yapay Sinir A ğları, 1. Bask1, Papatya Yayınc1lık, İstanbul, 2003.

[13] Ç. Elmas, Yapay Zeka Uygulamaları, 1. Bask1, Seçkin Yayıncılık, Ankara, 2007.

[14] T. Tsai, C. Lee and C. Wei, "Neural Network Based Temporal Feature Models for Short-Term Railway Passenger Demand Forecasting," Expert Systems with Applications, c. 36, ss. 3728-3736, 2009.

[15] M. Dougherty, "A Review of Neural Networks Applied to Transport," Transportation Research Part C: Emerging Technologies, c. 3, s. 4, ss. 247-260,1995.

[16] M. Yaşar, "Günlük Akışlardaki Boşlukların Yapay Sinir Ağları Kullanılarak Tamamlanması," Yüksek Lisans Tezi, Pamukkale Üniversitesi, 2004.

[17] S. Agatonovic-Kustrin and R. Beresford, "Basic Concept of Artificial Neural Network Modeling and Its Application in Pharmaceutical Research," Journal of Pharmaceutical and Biomedical Analysis, c. 22, ss. 717-727, 2000.

[18] L. Daniel, T. K. Chaturvedi and L. M. Kolhe, "Dynamic Economic Load Dispatch Using Levenberg Marquardt Algorithm," Energy Procedia, c. 144, ss. 95-103, 2018.

[19] S. Mammadli, "Financial Time Series Prediction Using Artificial Neural Network Based on Levenberg- Marquardt Algorithm," Procedia Computer Science, c. 120, ss. 602-607, 2017.

[20] R. E. Anderson, B. J. Babin, W. C. Black and J. F. Hair Jr., Multivariate Data Analysis, 7. Edition, Pearson Prentice Hall, America, 2010.

[21] S. Yavuz, "Regresyon Analizinde Doğrusala Dönüştürme Yöntemleri ve Bir Uygulama," Atatürk Üniversitesi Iktisadi ve İdari Bilimler Dergisi, c. 23, s. 1, ss. 165-179, 2009. 